\title{
LA LEGITIMACIÓN POPULAR DEL DENUNCIANTE EN LA NUEVA JUSTICIA ANTE LOS TRIBUNALES AMBIENTALES
}

\author{
THE POPULAR LEGITIMATION OF THE COMPLAINANT IN \\ LIGHT OF CHILE'S NEW ENVIRONMENTAL LAWS
}

IVÁN HUNTER AMPUERO***

\section{RESUMEN}

El presente trabajo tiene por objeto analizar la figura del denunciante en el marco de la Ley Orgánica de la Superintendencia del Medio Ambiente y su legitimación para recurrir a los Tribunales Ambientales. Para ello se propone la tesis de que el interés del denunciante -cuya denuncia da origen a un procedimiento sancionatorio- puede consistir en el puro cumplimiento de la ley. Ese interés, sin embargo, puede ser derrotado cuando no concurren las razones subyacentes considerados por el legislador al momento de darle la calidad de interesado. Esto puede ocurrir si se presentan intereses espurios, los que no pueden considerarse legítimos.

Palabras Clave: Denunciante, Legitimación, Procedimiento sancionador, Interesado.

\footnotetext{
* Abogado, Doctor en Derecho U. Carlos III, de Madrid, España. Profesor de Derecho Sancionatorio y Litigación Ambiental, de la U. Austral de Chile. Dirección postal: Isla Teja s/n Valdivia, Facultad de Ciencias Jurídicas y Sociales. Correo electrónico: ivanhunter@uach.cl.

** Este trabajo fue realizado en el marco y con el financiamiento del Proyecto FonDECYT Regular ${ }^{\circ}$ 1171244, titulado "Derecho Procesal Administrativo: acerca de las relaciones entre procedimiento administrativo y proceso jurisdiccional", del cual el autor de este trabajo es su investigador responsable. Artículo recibido el 18 de marzo de 2019 y aceptado para su publicación el 11 de junio de 2019 .
} 


\section{ABSTRACT}

This paper aims to analyze the figure of the complainant within the framework of the Organic Law of the Superintendence of the Environment and its legitimacy to appeal to the Environmental Courts. The thesis proposed that the interest of the complainant -whose claim gives rise to a sanctioning procedure- might consist of pure compliance of the law. That interest, however, can be defeated when the underlying reasons considered by the legislator at the time of assessing the quality of interested party do not concur. This happens if spurious interests that cannot be considered legitimate are found to be hidden.

Keywords: Complainant, Legitimation, Administrative Punitive Procedure, Concerned party.

\section{INTRODUCCIÓN}

En la dinámica actual de las controversias jurisdiccionales del medio ambiente, cobra vital importancia considerar las vinculaciones entre procedimiento administrativo ambiental y el proceso de revisión de los actos ante los Tribunales Ambientales (en adelante, TTAA). ${ }^{1}$ Esta relación, que debería estar continuamente presente en toda pretensión regulativa, no siempre ha sido correctamente entendida, y la falta de una coherencia clara entre ambos termina restando certeza y claridad a las normas procesales aplicables. En qué medida los criterios de legitimación propios del procedimiento administrativo resultan vinculantes en el contencioso administrativo ambiental, constituye un aspecto central de estas líneas.

En este trabajo me propongo enfrentar dos problemas: el primero es definir qué tipo de legitimación ostenta el denunciante para recurrir a los TTAA impugnando una resolución de la Superintendencia del Medio Ambiente (en adelante SMA) dictada en un procedimiento sancionatorio. El segundo problema, derivado del anterior, es determinar si el carácter imperativo del artículo 21 Ley Orgánica de la Superintendencia de Medio

\footnotetext{
1 Un caso interesante de las relaciones entre procedimiento administrativo y contencioso de revisión es el resuelto por el Segundo Tribunal Ambiental, para ello véase: Segundo Tribunal Ambiental, 31 de agosto de 2017, Rol N R-118-2016.
} 
Ambiente (en adelante LOSMA) permite discutir en el contencioso ambiental esa legitimación activa, de manera de establecer que el denunciante pueda carecer de legitimación en un caso concreto, aun cuando la ley lo considere un interesado.

Para la comprensión cabal de estos problemas es necesario considerar el juego de una serie de normas jurídicas. La primera es el artículo 21 LOSMA, que dispone: "Cualquier persona podrá denunciar ante la Superintendencia el incumplimiento de instrumentos de gestión ambiental y normas ambientales, debiendo ésta informar sobre los resultados de su denuncia en un plazo no superior a 60 días hábiles". En su inciso $2^{\circ}$ agrega: "En el evento que producto de tales denuncias se iniciare un procedimiento administrativo sancionador, el denunciante tendrá para todos los efectos legales la calidad de interesado en el precitado procedimiento" (la cursiva es mía). Por su parte, el artículo 56 inciso $1^{\circ}$ LOSMA, establece: "Los afectados que estimen que las resoluciones de la Superintendencia no se ajustan a la ley, reglamentos o demás disposiciones que le corresponda aplicar, podrán reclamar de las mismas, dentro del plazo de quince días hábiles, contado desde la notificación, ante el Tribunal Ambiental" (la cursiva es mía).

En otra arista, la Ley de Tribunales Ambientales (en adelante LTTAA), en su artículo $18 \mathrm{~N}^{\circ} 3$, señala que: "Los organismos de la Administración del Estado y las personas naturales o jurídicas que se señalan, podrán intervenir como partes en los asuntos de competencia de los Tribunales Ambientales, que en cada caso se indican, conforme con la enumeración del artículo 17: (...) 3), las personas naturales o jurídicas directamente afectadas por la resolución de la Superintendencia del Medio Ambiente".

Conforme a estas disposiciones el denunciante, por el solo ministerio de la ley, adquiere la calidad de interesado cuando, producto de su denuncia, la Administración decida iniciar un procedimiento administrativo sancionador. La calidad de interesado importa -desde una primera impresión- reconocer en el respectivo procedimiento administrativo la posibilidad de formular toda clase de alegaciones, solicitar todas las pruebas que estimen pertinentes y relevantes desde que la ley no ha reservado esta facultad únicamente al presunto infractor, ${ }^{2}$ como asimismo recurrir

2 Véase: Segundo Tribunal Ambiental, 3 de marzo de 2014, Rol N R-6-2013 (en adelante, simplemente caso Pascua Lama). El interesado tiene una amplia gama de garantías en todo el tránsito del procedimiento administrativo. Por un lado, el artículo 10 de la Ley N ${ }^{\circ} 19.880,2003$ (en adelante 
administrativamente en contra del acto terminal.

De igual forma, atendida esa calidad de interesado, no habría duda que pueden recurrir a los TTAA en la medida que la resolución de la SMA lo afecte. En consecuencia, si el denunciante adquiere la calidad de interesado por el sólo ministerio de la ley, y en esa calidad puede interponer una impugnación ante los TTAA cuando estima que la resolución de la SMA lo afecta: ¿Qué clase de legitimación es la que ostenta? ¿Puede ser discutida la legitimación del denunciante en sede jurisdiccional?

La hipótesis que barajaré es la siguiente: la calidad de interesado en el procedimiento administrativo sancionador ${ }^{3}$ que asume el denunciante por la aplicación del artículo 21 LOSMA, es suficiente para legitimar una reclamación ante los TTAA, siempre y cuando se trate de la defensa de un interés legítimo individual, colectivo e incluso el puro interés en el cumplimiento de la legalidad. Sin embargo, esta norma es derrotable (o debe ser interpretada restrictivamente si se quiere), en la medida que se justifique que el denunciante no persigue la tutela de su interés, sino de otros secundarios o espurios, no pudiendo, en consecuencia, considerarse un interesado.

Para cumplir esta finalidad he querido comenzar manifestando una preocupación inicial por la legitimación activa en la LTTAA (II) para luego establecer la relación entre denunciante e interesado (III). Posteriormente (IV) propondré las interpretaciones posibles del artículo 21 LOSMA en relación a los interesados, con la finalidad de demostrar (V) los problemas de la legitimación popular y la derrotabilidad de esa disposición. Esta última parte supone, además, (VI) mostrar las razones subyacentes en esa norma jurídica, y definir cuándo no concurren. Por último (VII) he querido, como corolario de lo anterior, proponer una reformulación en la interpretación del artículo 21 LOSMA.

\footnotetext{
LBPA), le asegura la posibilidad de aducir alegaciones y aportar documentos u otros elementos de juicio, en cualquier etapa del procedimiento. Por otro lado, el artículo 17 letra f) LBPA también les asegura a los interesados el derecho a formular alegaciones y aportar documentos en cualquier fase del procedimiento. Esta posibilidad de presentar alegaciones en todo el procedimiento ha sido especialmente reconocida por nuestros TTAA. Así, puede verse en la causa señalada que se hace un interesante análisis acerca del ámbito y oportunidad en que se pueden plantear alegaciones por parte del presunto infractor en el procedimiento administrativo sancionador.

${ }^{3}$ Entenderé el procedimiento administrativo sancionador en un sentido amplio, es decir, no solo los casos en que se concluye con la imposición de una sanción sino además cuando el procedimiento concluye por la aprobación o rechazo de un Programa de Cumplimiento.
} 


\section{LA PREOCUPACIÓN INICIAL DE LA DOCTRINA POR LA LEGITIMACIÓN ACTIVA EN LA LTTAA}

Como es sabida, la legitimación activa constituye un presupuesto procesal necesario para que el tribunal pueda dictar una sentencia sobre el fondo de la pretensión deducida. ${ }^{4}$ Resumidamente hay consenso en que la legitimación procesal está referida a la afirmación, por quien ejerce su derecho de acción, de ser titular de derechos subjetivos e intereses legítimos, produciendo el deber de inexcusabilidad en el tribunal.

No es este, sin embargo, el sentido que aquí quiero darle a la legitimación. En realidad, la tomaré en el sentido de las especiales condiciones que unen al sujeto que recurre con el objeto del reclamo, de manera que la decisión que se adopte por el tribunal puede influir, positiva o negativamente, en una esfera de interés legítimo de que es titular. En otras palabras, a los presupuestos para que el juez pueda estimar una pretensión de revisión de un acto administrativo. ${ }^{5}$

El mundo académico ha planteado una preocupación por el sentido y alcance del artículo 18 LTTAA que regula la legitimación para acceder a los TTAA. ${ }^{6}$ Las críticas apuntan en varios sentidos. Según BermúdeZ ${ }^{7}$ en muchos casos en que es posible recurrir a los TTAA se establecen exigencias materiales muy restrictivas y difícilmente realizables en la práctica, como por ejemplo, el contencioso de impugnación de normas ambientales (artículo $17 \mathrm{~N}^{\circ} 1$ LTTAA) en que el contraste del Decreto Supremo debe hacerse sólo

\footnotetext{
${ }^{4}$ Bordalí, Andrés, "Principios de una nueva justicia administrativa en Chile”, en: Bordalí, A.; Ferrada, J. C. (Coords.), Estudios de Justicia Administrativa, LexisNexis, Santiago, 2008, p. 380.

5 PAReJo, Luciano, Lecciones de Derecho Administrativo, Tirant lo Blanch, Madrid, 2012, p. 653; CoRdero, Eduardo, "La legitimación activa en el proceso contencioso-administrativo", en: FERRADA, J. C. (Coord.), La Justicia Administrativa Lexis Nexis, Santiago, 2005, p. 393, y FerradA, Juan Carlos, "La legitimación activa en los procesos administrativos anulatorios en el derecho chileno", en: FERRADA, J. C. (Coord.), La nulidad de los actos administrativos en el derecho chileno, Thomson Reuters, Legalpublishing, Santiago, 2013, p. 160.

${ }^{6}$ Esta preocupación desde luego va más allá de la impropiedad del lenguaje legislativo de denominar "partes" a una cuestión que está centrada en la legitimación como aspecto de fondo. Sobre esta diferencia: Romero, Alejandro, "Comentario a la sentencia de la Corte Suprema y de la Corte de Apelaciones de Santiago y de Puerto Montt. Nota sobre la legitimación en la jurisprudencia", Revista Chilena de Derecho, 1998, Vol. 25, p. 693, y Navarro, Manuel, Partes, legitimación y litisconsorcio en el proceso civil (Estudio jurisprudencial práctico), Colex, Madrid, 1998, pp. 91-96.

7 Bermúdez, Jorge, “Administración y Jurisdicción Ambiental: la institucionalidad ambiental frente al nuevo contencioso administrativo", en: FERRADA, J. C. (Coord.), La nulidad de los actos administrativos en el derecho chileno. IX Jornadas de Derecho Administrativo, Thomson Reuters-Legalpublishing, Santiago, 2013, pp. 497-501.
} 
con la LBGMA, pero no con el ordenamiento jurídico en general. Igual de restrictiva es la exigencia de perjuicio a quien interpone la impugnación, dado que las normas primarias de calidad ambiental no tienen como destinatarios a los ciudadanos, y la declaración de zona saturada o latente son trámites previos para la adopción de un plan de prevención o descontaminación, por lo que difícilmente pueden generar un perjuicio en el sentido patrimonial del término. ${ }^{8}$

Por otro lado, siendo la legitimación un criterio de selección de intereses jurídicamente relevantes, la opción legislativa de privilegiar el acceso casi exclusivamente a los titulares de proyectos y actividades empresariales es al menos criticable. Si se observa detenidamente el catálogo de competencias del artículo 17 LTTAA en relación al artículo 18 de la misma norma, podrá concluirse que el acceso a los TTAA está diseñado para los titulares de proyectos y actividades empresariales, posibilitando sólo residualmente el acceso a los ciudadanos. ${ }^{9}$

En este contexto, puede considerarse una ampliación ostensible de la legitimación activa que el denunciante pueda acceder a los TTAA planteando una reclamación en contra de una resolución de la SMA, al abrir la intervención de otros sujetos distintos al órgano público y al titular del proyecto o actividad empresarial. De esta forma, la expresión "directamente afectado" utilizada por el legislador para establecer la legitimación activa, no estaría vinculada exclusivamente al presunto infractor sino también al ciudadano denunciante o interesado que estima que la actuación de la SMA no satisface adecuadamente sus intereses o derechos vulnerados. Esta solución es la que postuló el Segundo Tribunal Ambiental en la sentencia del caso Pascua Lama, ${ }^{10}$ y venía siendo anunciada

\footnotetext{
8 Esta restricción inicial, sin embargo, fue paulatinamente superada por la jurisprudencia. Por un lado, el Segundo Tribunal Ambiental, 16 de diciembre de 2014, Rol N R-22-2014, resolvió que la legitimación para recurrir a los TA no queda circunscrita a la pura infracción de la LBGMA sino que a todo el ordenamiento jurídico, por lo que el contraste o revisión que debe realizarse del DS impugnado es mucho más amplio de lo que aparece en una primera lectura de la norma. Posteriormente en Corte Suprema, 30 de septiembre de 2015, Rol N ${ }^{\circ} 1119-2015$, se resolvió en los mismos términos del Segundo Tribunal Ambiental fijando el sentido y alcance de la expresión "perjuicio" consagrada en el numeral $1^{\circ}$ del artículo 18 de la Ley $\mathrm{N}^{\circ} 20.600$ de 2012 y artículo 50 de la Ley $\mathrm{N}^{\circ} 19.300$ de 1994. En igual sentido resolvió el Tercer Tribunal Ambiental, 29 de septiembre de 2016, Rol N R-25-2016, sentencia confirmada por la Excma. Corte Suprema.

9 Esta conclusión inicial de la Ley $\mathrm{N}^{\circ} 20.600$ de 2012 tiene un giro drástico a partir de la teoría de la "invalidación impropia" articulada por la Corte Suprema. Véase, BORDALí, Andrés; HunTER, Iván, Contencioso Administrativo Ambiental, Librotecnia, Santiago, 2017, pp. 163-171.

${ }^{10}$ La sentencia en cuestión señala: "Cuarto: Que la legitimación activa para impugnar resoluciones
} 


\section{por Jorge BERMÚDEZ en la doctrina nacional. ${ }^{11}$}

\section{DENUNCIANTE E INTERESADO: UNA RELACIÓN NO NECESARIA}

En términos generales puede concebirse a la denuncia como el acto por el cual un ciudadano cualquiera, espontánea o en cumplimiento de un deber legal, coloca bajo la esfera de conocimiento y acción de la Administración un hecho que importa el incumplimiento de un instrumento de gestión ambiental. ${ }^{12}$ La ciudadanía, individual u organizadamente, puede tener conocimiento de que la legalidad ambiental ha sido violada,

dictadas por la SMA se encuentra regulada en los artículos 56 de la Ley $\mathrm{N}^{\circ} 20.417$ y $18 \mathrm{~N}^{\circ} 3$ de la Ley $\mathrm{N}^{\circ} 20.600$. El primer precepto, en su inciso primero, señala: Los afectados que estimen que las resoluciones de la Superintendencia no se ajustan a la ley, reglamentos o demás disposiciones que le corresponda aplicar podrán reclamar de las mismas, dentro del plazo de quince días hábiles, contado desde la notificación, ante el Tribunal Ambiental. Por su parte, la segunda disposición expresa que pueden reclamar en contra de las resoluciones de la SMA las personas naturales y jurídicas directamente afectadas por la resolución de la Superintendencia. De los citados preceptos se puede concluir que la legitimación activa para impugnar resoluciones de la SMA está asociada al concepto de 'afectado(s)', y como consecuencia de lo señalado en el artículo $18 \mathrm{~N}^{\circ} 3$ de la Ley $\mathrm{N}^{\circ} 20.600$, el afectado por la resolución debe serlo 'directamente', es decir, que la afectación surja como consecuencia de lo resuelto en la resolución que se impugna. Vigésimo: Que, de acuerdo a lo señalado en la consideración anterior, es fundamental para determinar si los agricultores y regantes de la comuna de Alto del Carmen son directamente afectados por la resolución impugnada, que éstos hayan acreditado a través de cualquier medio idóneo que efectivamente habitan o realizan actividades dentro del área de influencia del proyecto, más allá de la mera afirmación que en esa dirección realizaran en su escrito de reclamación ante este Tribunal. En este sentido, los reclamantes señalaron ante el Superintendente que ellos formaban parte de la Junta de Vigilancia de la Cuenca del Río Huasco y sus Afluentes, persona jurídica que tiene la calidad de denunciante en el proceso administrativo sancionador y que fue admitida expresamente como parte interesada por la SMA mediante Oficio Ordinario $\mathrm{N}^{\circ} 58$ de fecha 27 de marzo de 2013, y que no impugnó la resolución reclamada en autos. Por lo tanto, de ser efectivo que forman parte de la citada Junta de Vigilancia, se derivarían dos importantes consecuencias. Primero, se acreditaría que estos reclamantes habitan o realizan actividades en el área de influencia del proyecto, criterio fundamental para determinar su calidad de 'directamente afectado', tal como ya se señaló en la consideración décimo séptima de esta sentencia. Segundo, en cierta medida, su situación sería asimilable a los reclamantes que fueron parte interesada en el proceso administrativo sancionador, ya que pertenecerían a una organización que fue denunciante y considerada como interesada en el proceso administrativo sancionatorio que culminó con la resolución impugnada".

${ }^{11}$ BermúdeZ, cit. (n 7), p. 502.

${ }^{12}$ Doménech define la denuncia "como aquel acto mediante el cual un particular pone en conocimiento de los poderes públicos la comisión de una infracción del ordenamiento jurídico por una o varias personas determinadas". DomÉNech, Gabriel, "Roma delatoribus praemiat. La denuncia en el Derecho Público", en: Díez, Juan J. (Ed.), Función Inspectora. Actas del VIII Congreso de la Asociación Española de Profesores de Derecho Administrativo, Instituto Nacional de Administración Pública, Madrid, 2013, p. 171. En términos más sencillos, la denuncia consiste en "poner en conocimiento del órgano competente un hecho o hechos que puedan dar motivo a la iniciación de un procedimiento". Domínguez, Antonio, Constitución y Derecho Sancionador Administrativo, Marcial Pons, Madrid, 1997, p. 306. 
pudiendo cooperar mediante la transmisión de esa información a la Administración. La herramienta para esa transmisión es la denuncia, la que, salvo casos excepcionales, nunca obligará al aparato burocrático a iniciar un procedimiento administrativo. ${ }^{13}$

Bajo esta perspectiva la relación entre denunciante e interesado no es siempre necesaria. El ciudadano que pone en conocimiento la existencia de un incumplimiento normativo no necesariamente se encuentra afectado por el mismo. Por esa razón, a la luz de la doctrina comparada, la diferentes posiciones que asumen, prima facie, el denunciante e interesado parece no tener discusión, ${ }^{14}$ aun cuando existen voces que critican esta tajante separación. ${ }^{15}$ Los autores al respecto han dicho que es la calidad de interesado y no la de denunciante lo que atribuye legitimación activa para recurrir frente a los actos de la Administración. ${ }^{16}$ Es decir, son otras las circunstancias que determinan la calidad de interesado del denunciante, y no precisamente el hecho de haber presentado una denuncia.

Así entonces, el criterio que denota la calidad de interesado sería la titularidad de un derecho subjetivo e interés legítimo que pueda resultar afectado o beneficiado por la resolución que se dicta fruto del procedimiento administrativo sancionatorio. ${ }^{17} \mathrm{El}$ denunciante, por la sola calidad de tal, no calza ni cumple con esta condición.

De esta manera, surge la distinción entre denunciante simple y denunciante cualificado. Sólo este último adquiere la calidad de interesado en el procedimiento administrativo, pero no porque haya colocado la notitia criminis en la esfera del ius puniendi, sino por la titularidad de derechos

\footnotetext{
${ }^{13}$ Véase, Santamaría, Juan, Principios de Derecho Administrativo General, Iustel, Madrid, 2009, $2^{\mathrm{a}}$ edición, T. II, p. 46.

${ }^{14}$ Véase esta distinción en: MARTíneZ, Nora, "Problemas jurídico-prácticos de la figura del denunciante en el procedimiento administrativo sancionador", Revista Xuridica Galega, 2001, № 33, pp. 60-89.

${ }^{15}$ Gallardo, María Jesús, Los procedimientos administrativos en la Ley 39/2015: análisis y valoración de la reforma, Tecnos, Madrid, 2016, p. 202.

${ }^{16}$ Nieto, Alejandro, Derecho Administrativo Sancionador, Tecnos, Madrid, 1993, p. 150; Gómez, Manuel; SAnz, Iñigo, Derecho Administrativo Sancionador. Parte General. Teoría General y Práctica del Derecho Penal Administrativo, Aranzadi, Madrid, 2013, $3^{\text {a }}$ edición, pp. 805-806; y MARTínez, cit. (n. 14), p. 64.

${ }^{17}$ En materia de procedimientos sancionatorios se discute quién -aparte del presunto infractor- puede ostentar la calidad de interesado. Por un lado, hay algunos que opinan que la simple calidad de víctima de la infracción administrativa es suficiente para tener la calidad de interesado; otros, en cambio, exigen que el interesado haya resultado perjudicado por la resolución sancionatoria; por último, hay parte de la doctrina que postula que el interesado es solo aquel que obtiene un beneficio como resultado de la imposición de una sanción. Véase, GómEZ y SANZ, cit. (n. 16), p. 807.
} 
e intereses legítimos que puedan ser afectados, positiva o negativamente, por la decisión estatal, ${ }^{18}$ esto es, la obtención de algún beneficio o utilidad potencial, o la eliminación de alguna carga o gravamen ambiental con la referida resolución.

Por tales razones, tanto la doctrina como la jurisprudencia comparada aconsejan que la respuesta de la legitimación activa del denuncianterecurrente deba resolverse casuísticamente, sin formulación de una regla general de admisión o denegación, debiendo inquirirse en las particularidades del caso. ${ }^{19}$ Como problema casuístico, en términos generales, la alegación y prueba de la calidad de interesado del denunciante cualificado le corresponderá a quien se irrogue dicha calidad. ${ }^{20}$

En este sentido también es un error entender que el interesado en el procedimiento administrativo sancionador por esa sola circunstancia se encuentra afectado por la resolución que dicte la SMA. Todo parece indicar que la calidad de agraviado - que determina la legitimación activa para recurrir al contencioso ambiental- es algo que debe justificarse en el respectivo proceso jurisdiccional. Y ello, porque la legitimación activa se relaciona directamente con la afectación, menoscabo o detrimento concreto en una determinada posición jurídica subjetiva ocasionada por un acto administrativo que se considera ilegal. Solo esta especial vinculación del reclamante con el objeto del proceso es lo que permite a los jueces dictar una sentencia favorable.

Si esto es así, entonces hay que señalar que la calidad de interesado en el procedimiento administrativo no define ni determina necesariamente la legitimación activa en materia de revisión de actos jurisdiccionales. Para que ello ocurra habrá que justificar y probar cómo la resolución materia de la impugnación afecta la posición jurídica de ese interesado, ${ }^{21}$ esto es, en qué medida y forma la decisión administrativa perjudica su situación de

\footnotetext{
${ }^{18}$ Según Nieto el efecto legitimador es el beneficio que produzca al actor la imposición de una sanción, de manera que un verdadero interesado debería demostrar que con la sanción se producirá una utilidad en su esfera de interés. NieTo, cit. (n. 16), p. 113.

${ }^{19}$ Сово, Tomás, El procedimiento administrativo sancionador, Editorial Bosch, Barcelona, 2008, p. 154.

${ }^{20}$ Сово, cit. (n. 19), p. 156.

${ }^{21}$ Сово, cit. (n. 19), p. 154, señala: "El interés legítimo en general, como ha venido señalando la jurisprudencia, no es un mero interés en el respeto de la legalidad, es necesario que el demandante esté revestido de una cualificación específica, es decir, de una especial relación con el objeto del proceso que viene concretada en la titularidad de un interés directo, personal y legítimo que pueda resultar afectado por la resolución que se dicte".
} 
ventaja o beneficio. ${ }^{22}$ No hay, por tal razón, una relación muy estrecha entre procedimiento administrativo y proceso jurisdiccional.

Lejos del esquema señalado, que es el tradicional para los procedimientos sancionatorios, el inciso $2^{\circ}$ del artículo 21 LOSMA confiere al denunciante la calidad de interesado, por el solo hecho de interponer una denuncia y lograr la apertura de un procedimiento sancionador. En rigor el denunciante no debería adquirir más condición que la de un testigo de la existencia de algún hecho que puede revestir las características de un incumplimiento a la normativa ambiental. Constituye, por lo mismo, una fuente de información relevante para la determinación de los hechos.

Como mero testigo cualificado, el denunciante no debería tener derecho -salvo los casos en que pueda ser considerado interesado- a acceder al expediente administrativo ni menos a ejercer las facultades que consagran los artículos 10 y 17 letra f) Ley de Bases de Procedimientos Administrativos (en adelante LBPA). Y ello porque esos derechos, el ordenamiento nacional solo los consagra y reconoce respecto de quienes ostentan la calidad de interesados en el procedimiento administrativo, condición que no necesariamente reúne el denunciante. El legislador, sin embargo, al transformarlo en interesado toma una decisión política que puede enmarcarse en una estrategia pública de mayor relevancia, desde que puede resultar cuestionable para la satisfacción del interés general que se excluya al denunciante como fuente de información para la determinación verdadera de los hechos ${ }^{23}$. Sin embargo, como analizaremos más adelante, esta estrategia tiene por finalidad incentivar la participación de los ciudadanos en la fiscalización del cumplimiento de la normativa ambiental, asegurándole el estatus de interesados y el conjunto de prerrogativas procedimentales que de tal condición se derivan.

\section{POSIBLES INTERPRETACIONES DEL ARTÍCULO 21 LOSMA: UN CASO DE LEGITIMACIÓN POPULAR POR EL INTERÉS PÚBLICO}

Como se puede apreciar de lo dicho, la LOSMA ha prescindido de la distinción entre denunciante simple y denunciante cualificado, por lo que

\footnotetext{
${ }_{22}$ Esto representa, desde luego, una ampliación a la posibilidad de acceder a la justicia ambiental, desde que cualquier sujeto que sienta que la decisión administrativa ambiental perjudica su situación jurídica, puede impugnar esa decisión ante el Tribunal Ambiental.

${ }^{23}$ Sobre la importancia de la verdad en la toma de decisiones administrativas, especialmente en el ámbito del uso racional y no arbitrario del poder estatal, véase: CARLONI, Enrico, Le verità amministrative. L'attività conoscitiva pubblica tra procedimento e proceso, Giuffrè Editore, Milán, 2011, pp. 54 y ss.
} 
ambos adquieren la calidad de interesados si producto de la denuncia se abre un procedimiento sancionatorio. La pregunta que puede hacerse entonces es ¿según el legislador cuál es el interés que defiende el denunciante? La respuesta a esta pregunta puede tener una doble respuesta.

\section{Artículo 21 LOSMA como norma de presunción de interés}

La primera es entender que la expresión "interesado", del artículo 21 LOSMA, está tomada en el mismo sentido que el artículo 21 de la LBPA. ${ }^{24}$ Esta norma indica: "Se consideran interesados en el procedimiento administrativo: 1. Quienes lo promuevan como titulares de derechos o intereses individuales o colectivos". Conforme a ella pueden ser interesados los denunciantes cuyos derechos e intereses tengan una específica conexión con el objeto del procedimiento, o tratándose de las impugnaciones jurisdiccionales, con la relación jurídica procesal que será generalmente el acto administrativo materia de la reclamación. ${ }^{25}$ Este interés, individual o colectivo, se traduce, como ya se ha dicho, en cualquier situación de ventaja, provecho o utilidad legítima, propia y específica del sujeto, derivada del acto administrativo. ${ }^{26}$

Si esto es así, entonces la norma en cuestión no representa en términos sustantivos ningún avance respecto de la legislación vigente, dado que los

\footnotetext{
${ }^{24}$ Esta respuesta es la que se sugiere en el fallo del Segundo Tribunal Ambiental, 3 de marzo de 2014, Rol N R-6-2013 (Pascua Lama). En esta sentencia se señala: "Undécimo: Que, al respecto, es necesario tener presente que el artículo 21 de la Ley $\mathrm{N}^{\circ} 19.880$, precisa que interesados en el procedimiento administrativo son quienes: i) lo promuevan como titulares de derechos o intereses individuales o colectivos; ii) los que sin haber iniciado el procedimiento, tengan derechos que puedan resultar afectados por la decisión que en el mismo se adopte; y iii) aquellos cuyos intereses individuales o colectivos, puedan resultar afectados por la resolución y se apersonen en el procedimiento en tanto no haya recaído resolución definitiva. Por lo tanto, en este caso, es la propia ley (art. 21 de la LOSMA) la que ha puesto al denunciante en calidad de interesado en el procedimiento administrativo sancionador, y lo ha hecho "para todos los efectos legales". Duodécimo: Que de la definición de interesado contenida en el artículo 21 de la Ley $\mathrm{N}^{\circ} 19.880$, se sigue que el denunciante interesado en un procedimiento administrativo sancionador tiene, a lo menos, un derecho o interés que puede ser afectado por la resolución que se dictará en el respectivo procedimiento. Es decir, respecto del denunciante es la propia ley la que reconoce una eventual relación de afectación entre su derecho o interés y la resolución absolutoria o sancionatoria que ponga término al proceso sancionatorio, siendo en este contexto y en su calidad de interesado que se le permite hacer valer una pretensión frente a la autoridad administrativa. En este caso, el denunciante interesado solicitó que se calificara la gravedad de las infracciones de la Compañía de una determinada manera y que se le aplicaran determinadas sanciones".

${ }^{25}$ PAREJo, cit. (n. 5), pp. 340-341.

${ }^{26}$ Véase, González, Jesús, Manual de Procedimiento Administrativo, Civitas, Madrid, 2002, $2^{\mathrm{a}}$ edición, p. 161.
} 
intereses individuales y colectivos pueden ser perfectamente invocados por un particular en un procedimiento administrativo, quien tendrá la calidad de interesado por ese motivo. De ahí que sea posible impugnar la resolución que se dicte cuando se produce la afectación de su interés tutelado. En esta interpretación el único efecto útil del artículo 21 LOSMA sería que el denunciante no tiene que acreditar ni justificar la calidad de interesado, pues la norma lo presume o subentiende. ${ }^{27}$ Lo que haría la norma en cuestión sería simplemente normativizar un rasgo común en los que frecuentemente actúan como denunciantes: tener un interés en la actuación administrativa. ${ }^{28}$ Este efecto, sin embargo, está lejos de tener cabida en los términos categóricos de la disposición, que parece no admitir cuestionamientos acerca del carácter de interesado del denunciante.

\section{Artículo 21 LOSMA como norma que permite la invocación del interés público}

La segunda interpretación es más amplia y consiste en entender que además del interés individual y colectivo, el denunciante puede actuar en el puro interés del cumplimiento de la legalidad ambiental. En virtud de esta interpretación, el legislador daría la calidad de interesado al denunciante que no tiene posiciones jurídicas cualificadas que puedan verse afectadas o alteradas por el procedimiento administrativo, pero que persigue el cumplimiento de la legalidad ambiental como una forma de manifestación del interés público de la actividad administrativa. El denunciante contribuye en la obtención y traspaso de información a la Administración activa, de manera que facilita el cumplimiento de los fines públicos de su actividad

\footnotetext{
${ }^{27}$ Esta parece ser la tesis seguida por BERMúdez, Jorge, Fundamentos de Derecho Ambiental, Ediciones Universitarias de Valparaíso, Valparaíso, 2014, $2^{\text {a }}$ edición, p. 503. Explica Cobo que "si desde el punto de vista teórico, puede producirse una denuncia por un particular por razones meramente cívicas con el fin de que se cumplan las normas, la realidad es que detrás de cada denuncia de un particular hay un derecho o intereses protegible de este". Сово, cit. (n. 19), p. 153.

${ }^{28}$ En la práctica jurídica nacional el denunciante la mayor de las veces tiene derechos o intereses afectados por la resolución de la Administración. Así, por ejemplo, Segundo Tribunal Ambiental, 22 de julio de 2016, Rol N R-68-2015, que indicó: “dado que la Sociedad Vinícola Miguel Torres S.A. fue denunciante y tuvo la calidad de interesada en el proceso administrativo sancionador, y asimismo, que de los antecedentes que obran en autos, se desprenden la existencia de una afectación -olores molestos para la reclamante- el Tribunal no puede sino concluir que ha de considerarse directamente afectada por la Resolución Exenta $N^{\circ} 12$, Rol N D-26-2014 que aprueba un programa de cumplimiento, suspendiendo el correspondiente procedimiento sancionador rechazándose en consecuencia la alegación de falta de legitimación activa".
} 
inspectora (función preventiva y especialmente la imposición de sanciones como mecanismo disuasivo) y el restablecimiento de la legalidad vulnerada. ${ }^{29}$ El principal argumento de esta tesis es de texto: el artículo 21 LOSMA faculta a cualquier persona para denunciar ante la Superintendencia el incumplimiento de instrumentos de gestión ambiental, y lo transforma en interesado si su denuncia da origen a un procedimiento sancionador. No le exige justificar ni probar la afectación de un derecho o interés. En esta perspectiva, el denunciante simple podrá siempre impugnar una resolución de la SMA cuando estime que ésta no satisface adecuadamente el interés público subyacente en la correcta aplicación de la normativa ambiental, pudiendo, en consecuencia, considerarse directamente afectado. ${ }^{30}$

Las consecuencias de esta última interpretación en el ámbito de la legitimación activa ante el TTAA son evidentes. A través de la figura del denunciante sería posible incorporar al contencioso ambiental una especie de legitimación popular, aunque sea indirectamente y más limitada. Aquí el legislador entiende que "se habilita a cualquier persona, física o jurídica, para impugnar los actos referidos a materias determinadas, por entender que el interés público implicado en tales casos es tan intenso que llega a afectar singularmente a todos y cada uno de los miembros de la comunidad". ${ }^{31}$ En la medida que el denunciante, por el solo ministerio de la ley, adquiere la

\footnotetext{
${ }^{29}$ DoméNeCH, cit. (n. 12), p. 173.

${ }^{30}$ Bermúdez indica que el interés del denunciante se extiende a sede jurisdiccional: Bermúdez, cit. (n. 27), p. 503. Por otra parte, también se precisa por la doctrina que las sanciones administrativas son una técnica de protección o tutela de ciertos bienes jurídicos apreciados por la comunidad, por lo que siempre existirá un interés público o general en su determinación. PAREJo, Luciano, Derecho Administrativo, Ariel, Barcelona, 2003, p. 775.

${ }^{31}$ SANTAMARía, cit. (n. 13), p. 699. Esta parece una consecuencia forzada cuando se elimina cualquier exigencia al denunciante para entender que es interesado. Señala Lozano que "La única vía para obtener en todo caso la legitimación del denunciante en el procedimiento sancionador administrativo la constituye el expreso reconocimiento legal de la denominada 'acción pública' (...), en cuanto supone que cualquier ciudadano puede interponer la acción para instar la potestad represiva, con independencia de que haya sido o no ofendido por el ilícito". LozANo, Blanca, "El principio de oficialidad de la acción sancionadora administrativa y las condiciones necesarias para garantizar su efectividad", Revista de Administración Pública, 2003, $\mathrm{N}^{\circ}$ 161, p. 106. En el Derecho Comparado una de las fórmulas que se ha encontrado para la defensa de los bienes jurídicos de titularidad colectiva, como el medio ambiente, ha sido establecer acciones populares, haciendo desaparecer toda exigencia de derecho o interés legítimo afectado. Aquí se le otorga a cualquier ciudadano un poder reaccional que busca hacer que se respete la norma jurídica y poner freno a los excesos o la desidia de la administración. Véase: CALVo, María, Sanciones ambientales, Marcial Pons, Madrid, 1999, pp. 164-165; GonZÁLEZ, Isabel, La protección de los intereses legitimos en el proceso administrativo, Tirant lo Blanch, Valencia, 1997, pp. 150-183 (con detención pp. 163 y ss.) y Pérez, Lorenzo, La defensa de los intereses ambientales (Estudio específico de la legitimación 'difusa' en el proceso contencioso administrativo), Editorial Lex Nova, Valladolid, 2002, pp. 107-116.
} 
calidad de interesado sin necesidad de ostentar la titularidad ni precisar la naturaleza de sus intereses, la legitimación deja de cumplir una función de selección de posiciones jurídicas relevantes. Por ello, resultaría admisible de que la pura defensa de la ley sea suficiente para justificar la participación del denunciante en el procedimiento administrativo, ${ }^{32}$ y luego, ante los TTAA cuando la resolución de la SMA no se ajusta a los intereses que subyacen en la imposición de sanciones. Esto es precisamente lo que caracteriza a las acciones populares. ${ }^{33}$ Es cierto que parte de la doctrina se resiste a esta posibilidad por entender que debe concurrir un interés directo, no siendo suficiente el mero interés de la actuación legal de la SMA; ${ }^{34} \sin$ embargo, esta conclusión la entendemos referida a quienes no tienen la calidad de denunciantes, pues estos sujetos no pueden intervenir directamente en el TTAA invocando un interés público.

En el Derecho Comparado esta clase de legitimación ha crecido sustancialmente en el ámbito de regulaciones especiales como el derecho urbanístico, el patrimonio cultural y en general en la protección del medio ambiente, donde se considera que existe un interés intrínseco en el cumplimiento de la normativa sectorial. En cambio, en nuestro derecho no ha sido reconocida más allá de los casos específicos regulados por el ordenamiento (acción por daño contingente y reclamo de ilegalidad municipal) y otras, aunque discutibles, doctrinariamente aceptados..$^{35}$

\footnotetext{
${ }^{32}$ Véase en el Derecho Comparado: Orena, Aitor, Discrecionalidad, Arbitrariedad e Inicio de Actuaciones Inspectoras, Aranzadi, Navarra, 2006, pp. 64-65.

${ }^{33}$ Este razonamiento se lee en la sentencia del Segundo Tribunal Ambiental, 24 de febrero de 2017, Rol R-104-2016, cuando señala: "dado que la reclamante de autos fue denunciante y tuvo la calidad de interesada para todos los efectos legales en el proceso administrativo sancionatorio dentro del cual se aprobó el programa de cumplimiento, interés que, sin duda, puede verse afectado por la aprobación de un mecanismo de incentivo de cumplimiento que no cumpla con los requisitos legales ni reglamentarios para su aprobación (...)". Cordón, refiriéndose a la legitimación popular explica que "las normas que reconocen la acción popular no son procesales, sino materiales, porque a través de ellas la ley considera a todos los ciudadanos como titulares de una relación sustancial en determinados ámbitos y, por tanto, como interesados, reconociéndoles el derecho de acción para reaccionar, en interés de todos los ciudadanos, frente a la actuación administrativa ilegal". Cordón, Faustino, El Proceso Contencioso Administrativo, Conforme a la Ley 29/1998 de 13 de julio, reguladora de la Jurisdicción ContenciosoAdministrativa, Aranzadi, Madrid, 2001, $2^{\text {a }}$ edición, p. 123.

${ }^{34}$ BermúdeZ, cit. (n. 7), p. 502.

${ }^{35}$ Una de las tesis que tradicionalmente rodeó a la nulidad de derecho público en nuestro país fue una pretendida legitimación objetiva, en que cualquier sujeto podría demandar la nulidad de un acto administrativo antijurídico. En el ideario inicial de la nulidad de derecho público (imprescriptible, insanable y de efectos ipso iure) resulta evidente la justificación de una legitimación cercana a la popular. Véase: JARA, Jaime, La nulidad de Derecho Público ante la doctrina y la jurisprudencia, Editorial Libromar, Santiago, 2004, pp. 219-225. Esta tesis, sin embargo, se encuentra superada.
} 
La figura del denunciante y su calidad de interesado ha servido al legislador para posibilitar, al menos de un modo acotado, la intervención de terceros en el proceso ante los TTAA. Se trata de una disposición que, si bien no consagra expresamente una legitimación activa popular, al menos implícitamente posibilita que sujetos que no tienen derechos e intereses individuales y colectivos, puedan encontrarse legitimados para recurrir a los TTAA en la medida que producto de su denuncia se haya iniciado un procedimiento administrativo sancionador. Dicho en otros términos, vía interés en el cumplimiento de la ley en sede administrativa, el legislador implícitamente ha activado un mecanismo de legitimación popular atenuado en el ámbito del contencioso administrativo. ${ }^{36}$

\section{LOS PROBLEMAS DE LA LEGITIMACIÓN POPULAR Y LA DERROTABILIDAD DEL ARTÍCULO 21 LOSMA}

El problema de entender que a través de la figura del denunciante puede ampararse la legitimación popular es que, bajo el manto del interés en el cumplimiento de la legalidad ambiental, pueden esconderse los más variados intereses espurios, oscuros o de cualquier otro orden, no necesariamente legítimos, actuando quienes lo afirman en la calidad de interesados en el respectivo procedimiento sancionatorio y en el contencioso administrativo ambiental. Dicho en otros términos, el denunciante puede actuar amparado bajo la legitimidad del interés en el cumplimiento de legalidad pero esconder su real propósito que no es otro que la consecución de beneficios o ventajas no amparables por el ordenamiento. Lo anterior se produce porque de la circunstancia que la ley atribuya a cualquiera el poder de recurrir ante un tribunal para el control de la legalidad de la actuación administrativa, no se sigue necesariamente que no exista una situación jurídica sustancial en el sujeto que promueve la pretensión contencioso administrativa. Es el caso, por ejemplo, del sujeto que formula una denuncia con la finalidad de generar un daño a la reputación de la competencia, para obtener algún tipo de información sensible o simplemente para impedir el desarrollo de un negocio. No se debe olvidar que el procedimiento sancionatorio puede

${ }^{36}$ Evidentemente que esto demuestra, una vez más, las intensas relaciones entre procedimiento administrativo y contencioso administrativo, que no es otra cosa que la complejidad histórica y actual de la relación entre Administración y Jurisdicción. Véase: Bordalí, Andrés, "La Administración Pública ante los Tribunales de Justicia Chilenos", Revista Chilena de Derecho, 2006, Vol. 33, № 1, pp. 17-36, y muy especialmente, pp. 26-34. 
significar una serie de cargas y gravámenes con alta injerencia en la esfera del regulado: requerimientos de información, inspecciones, medidas provisionales, medidas urgentes y transitorias, etc.

Ya explicaba Bordalí que "la acción popular, es decir, una legitimación abierta a toda persona para exigir el respeto a la legalidad, debe ser utilizada solo marginalmente. La hipótesis de un uso abusivo o fraudulento de la vía judicial, entre otras razones, debe llevar a descartar su utilización principal". ${ }^{37}$ En el Derecho Comparado también existe una clara conciencia de los peligros de esta clase de acciones, ${ }^{38}$ por haber servido de instrumento para el abuso especialmente en materia urbanística. ${ }^{39}$ Por otro lado, en España la acción contencioso administrativa ambiental tiene una naturaleza popular, atendida la naturaleza colectiva del medio ambiente y la necesidad de articular instrumentos de protección coherentes con esa característica. Sin embargo, aun cuando se asume el interés público de la regulación ambiental, si la acción es ejercida por personas jurídicas, éstas no deben tener fines de lucro. ${ }^{40}$

Ahora bien, los términos del artículo 21 LOSMA son demasiado categóricos, y literalmente entendidos, no permiten efectuar ninguna distinción, sea que los denunciantes enarbolen o no un interés público, siempre tendrán la calidad de interesados. Por esta razón, y como una forma de justificar la hipótesis de este trabajo, sostendré que el artículo 21 LOSMA es una norma que predica una generalización que contiene una justificación implícita, que concurre en la mayoría de los casos, pero no en todos. Por eso es posible que en el caso concreto pueda derrotarse cuando sus razones subyacentes no concurren.

\footnotetext{
${ }^{37}$ Bordalí, cit. (n. 4), p. 181, y Tolosa, César, "Proceso contencioso y medio ambiente: cuestiones procesales", Revista Jurídica de Castilla y León, 2010, № 21, p. 18.

${ }^{38}$ Véase: Gómez, Ana, La legitimación en el proceso contencioso-administrativo, Iustel, Madrid, 2014, pp. 538-541.

${ }^{39}$ Relata Gómez que la acción pública urbanística se utilizó como instrumento de coacción a dueños de inmuebles y constructoras. Un grupo de sujetos impugnaba judicialmente los permisos o licencias urbanísticas, para luego ofrecer desistimiento de los recursos judiciales a cambio de sumas de dinero. También indica que, en España, en plena etapa del boom inmobiliario, el ejercicio de esta acción era una técnica frecuente entre empresas competidoras. Véase: GómEz, cit. (n. 38), pp. 538 y 539. Cordón, por su parte, señala que la jurisprudencia ha reconocido a la buena fe como un límite al ejercicio de las acciones populares. CORDÓn, cit. (n. 33), p. 123. Véase acerca de los inconvenientes de esta clase de acciones: Prieto, Hugo, "La acción popular en el proceso administrativo" en: Cassagne, J. C. (dir.), Derecho Procesal Administrativo 1, Editorial Hammurabi, Buenos Aires, 2004, pp. 674-676.

${ }^{40}$ RuIz, Francisco, El proceso contencioso-administrativo, Thomson Aranzadi, Pamplona, 2016, p. 237.
} 
Para esta finalidad me valdré de la distinción formulada por ÁNGELES RóDENAS, ${ }^{41}$ en el sentido de que toda regla tiene una formulación normativa y una justificación subyacente. Las formulaciones normativas de la regla poseen autonomía semántica: esto es, que su significado -lo que las mismas prescriben- puede establecerse sin tomar en cuenta la justificación que subyace a las mismas. ${ }^{42}$ La regla que indica que el denunciante tiene la calidad de interesado cuando su denuncia da origen a un procedimiento administrativo sancionador, tiene una autonomía semántica que no considera las razones que haya tenido en cuenta el legislador para adoptar la regla. Se aplica, en consecuencia, a todos los denunciantes aunque se trate de sujetos cuyos intereses no sean los de perseguir el cumplimiento de la legalidad sino otros, espurios o no amparables.

Ello, sin embargo, no lleva a desconocer que en algunos casos se produzca un desajuste entre aquello que la formulación normativa nos exige y lo que la justificación subyacente a la misma requiere. Esto es lo que RóDENAS denomina "experiencias recalcitrantes". ${ }^{43}$ Se trata de reconocer que, en ciertos casos particulares, la generalización contenida en la formulación normativa comprende estado de cosas que no producen la consecuencia representada en la formulación de la regla. Ahora bien, una arista de este problema de adecuación entre formulación normativa y justificación subyacente se produce cuando la primera es supraincluyente, esto es, la prescripción incorpora ciertos supuestos en los que no sería aplicable la justificación. ${ }^{44} \mathrm{~A}$ mi juicio la norma del artículo 21 LOSMA tiene precisamente la característica de suprainclusión, abarcando con su texto casos a los que difícilmente resulta aplicable su justificación. Estos casos serían, precisamente, los que se relacionan con el ejercicio abusivo o fraudulento de la vía administrativa y judicial, en que la denuncia no es sino una herramienta para instrumentalizar intereses que el ordenamiento no tutela o protege.

${ }^{41}$ RóDEnAS, Ángeles, "En la penumbra: indeterminación, derrotabilidad y aplicación judicial de normas", Doxa. Cuadernos de Filosofía del Derecho, 2001, N²4, pp. 63-83. También puede verse para la derrotabilidad: BAYON, Juan Carlos, "Derrotabilidad, indeterminación del derecho y positivismo jurídico," Isonomía, 2000, $\mathrm{N}^{\circ} 13$, pp. 87-117.

${ }^{42}$ Ródenas, cit. (n. 41), p. 20.

${ }^{43}$ Ródenas, cit. (n. 41), p. 21.

${ }^{44}$ RóDENAS, cit. (n. 41), p. 21. Como indica Schauer los predicados fácticos de una regla prescriptiva pueden ser sobreincluyentes, esto es, comprender casos que escapan a la justificación de la regla, de manera que la relación entre justificación y consecuencia está ausente. Véase, ScHAUER, Frederick, Las reglas en juego. Un examen filosófico de la toma de decisiones basadas en reglas en el derecho y en la vida cotidiana, Marcial Pons, Madrid, 2004, p. 90. 
Por otro lado, a la misma conclusión podría llegarse mediante una interpretación correctora pero restrictiva de la norma jurídica. Esta tiene lugar cuando se "reduce el significado literal de una formulación normativa, excluyendo de su campo de aplicación supuestos que, según la interpretación literal, entrarían en él (reduce la denotación usual de las palabras)". ${ }^{45} \mathrm{La}$ interpretación de esta clase atribuye al texto o formulación normativa un sentido distinto al que se le daría según el uso común de las palabras, gracias a una disociación ${ }^{46}$ introducida por el intérprete con la finalidad de reducir su campo de aplicación. ${ }^{47}$

De esta manera sería posible que el intérprete de la norma pudiera introducir, como elemento de disociación, los intereses que representan los denunciantes, de manera que aquellos que no buscan el cumplimiento de la legalidad sino la tutela de otros fines que no son amparables por el ordenamiento jurídico, no se les aplica el Art. 21 LOSMA, y en consecuencia, no tienen la calidad de interesados, careciendo de legitimación activa para recurrir a los TTAA.

\section{LAS RAZONES SUBYACENTES EN EL ARTÍCULO 21 LOSMA: LOS INCENTIVOS DE LA DENUNCIA COMO SISTEMA DE CLAUSURA DE LA FISCALIZACIÓN AMBIENTAL}

Corresponde ahora determinar en qué consisten las razones subyacentes del artículo 21 LOSMA, de manera de precisar si, cuando esas razones no se encuentran presentes respecto de un denunciante, es posible derrotar la regla que le confiere la calidad de interesado. Con todo, creemos que las razones subyacentes de las normas jurídicas, cuando no aparecen claramente atribuidas en la historia legislativa, hay que extraerlas del contexto regulatorio. Ese es el propósito de las próximas líneas.

A mi entender, el artículo 21 LOSMA es una norma cuya finalidad

\footnotetext{
${ }^{45}$ Moreso, Juan; Vilajosana, Josep, Introducción al Derecho, Marcial Pons, Madrid, 2004, p. 166. Guastini, define a la interpretación correctora restrictiva como "aquella que restringe o circunscribe el significado prima facie de una disposición excluyendo de su campo de aplicación a algunos supuestos de hecho que, según la interpretación literal, entrarían dentro de él". Guastini, Riccardo, Estudios sobre la interpretación jurídica (Trad. Miguel Carbonell y María Gascón), Universidad Nacional Autónoma de México, Ciudad de México, 1999, $1^{\text {a }}$ Edición, p. 39.

${ }^{46}$ La disociación consiste, según Guastini, "en introducir subrepticiamente en el discurso del legislador una distinción en la que éste no ha pensado en absoluto, con el fin de reducir el campo de aplicación de una disposición sólo a algunos de los supuestos de hecho previstos por ella". GuastinI, cit. (n. 45), p. 43.

${ }^{47}$ Moreso y Vilajosana, cit. (n. 45), p. 166.
} 
es impulsar la participación ciudadana y la colaboración privada en la fiscalización ambiental a través de un incentivo y retribución hacia el denunciante. El legislador, en la medida que considera al medio ambiente como un bien valioso, tiene la misión de crear los incentivos adecuados para la realización de conductas que tiendan a su protección. En este sentido, si se considera que una denuncia sobre el incumplimiento de un instrumento de gestión ambiental es socialmente beneficiosa y que tiende a la protección del medio ambiente, transformar al denunciante en un interesado es un incentivo adecuado para estimular la participación de la ciudadanía en la fiscalización ambiental.

Hay una multiplicidad de factores relevantes que pueden explicar la necesidad de incentivar las denuncias por parte de los ciudadanos: a) en primer lugar, disminuye el costo social de tolerar la infracción de una norma ambiental. En efecto, infringir normas o regulaciones que han sido diseñadas para proteger al medio ambiente y la salud de las personas supone colocar en riesgo esos bienes jurídicos. Las denuncias permiten que la Administración ponga freno a esos incumplimientos mediante medidas urgentes y transitorias (artículo 3 letras g) y h) LOSMA), haciendo posible que el presunto infractor vuelva al estado de cumplimiento mediante los Programas de Cumplimiento (artículo 42 LOSMA) y, en su caso, los sancione. Por otro lado, todo incumplimiento a la legalidad compromete, en último término, la confianza que los ciudadanos depositan en las instituciones administrativas que regulan y controlan el ejercicio de actividades empresariales socialmente sensibles. La denuncia permite restablecer la confianza hacia la Administración dotándola de la información necesaria para el ejercicio de sus potestades públicas; b) En segundo lugar, la denuncia también es positiva porque los costos económicos de detectar la infracción a la normativa son asumidos por los ciudadanos. La exigencia de seriedad y mérito que se exige a la denuncia suponen que ha sido el ciudadano el que ha realizado la pesquisa inicial de la infracción a la norma ambiental, aun cuando es probable que la SMA siempre realice diligencias complementarias para comprobar la veracidad de los hechos, encomendando actividades de fiscalización. c) Por último, y tal como se había indicado anteriormente, la imposición de sanciones es una técnica administrativa para encausar las conductas de los regulados hacía el cumplimiento de las normas ambientales, y en consecuencia, siempre habrá un interés público en la detección, investigación y sanción. ${ }^{48}$

${ }^{48}$ Cabe señalar que "en una sanción, lo que sirve para tutelar los intereses públicos es la amenaza 
En esta lógica, la calidad de interesado que adquiere el denunciante constituye un incentivo y una especie de "retribución" hacia los ciudadanos que han colocado en la esfera de conocimiento de la Administración un hecho que reúne la seriedad y mérito suficiente para incoar un procedimiento administrativo sancionador, o la realización de acciones de fiscalización (artículo 47 inciso final LOSMA). Con este mecanismo se dispensa la colaboración y participación de los ciudadanos en la gestión administrativa, ${ }^{49}$ especialmente en los proyectos o actividades empresariales de concreción sensible para la población. A través de esta figura los ciudadanos, individual $\mathrm{u}$ organizadamente, pueden participar de la gestión de la actividad administrativa y controlarla cuando estimen que no satisface el interés público.

En esta perspectiva, la denuncia constituye la forma de clausurar un régimen de fiscalización del cumplimiento de la normativa ambiental. Por medio de ella, la SMA logra cubrir aquellos espacios de las actividades empresariales que no están sujetas a programas y subprogramas de fiscalización (artículo 16 LOSMA). Se trata de una opción política, que permite a la ciudadanía ${ }^{50}$ organizarse para cumplir un rol de fiscalización de los proyectos o actividades ambientales más sensibles, sirviendo además al aparato estatal para expandir su fuerza de fiscalización y sanción.

\section{DERROTANDO EL ARTÍCULO 21 LOSMA}

Hagamos una breve recapitulación para responder la segunda interrogante planteada en este trabajo. Hemos indicado que las razones

\footnotetext{
de imponerla en caso de que se cometa la conducta ilegal, no el contenido mismo de la sanción (...) las medidas de restablecimiento de legalidad, aunque se dirijan inmediatamente contra el infractor (imponiéndole obligaciones o privándole de bienes y derechos), afectan de forma directa a los intereses públicos, puesto que hacen que las normas se cumplan y que se logren los objetivos perseguidos por ellas, y también a intereses de terceros, cuando el incumplimiento de normas les perjudicaba (...)". Huergo, Alejandro, Las sanciones administrativas, Iustel, Madrid, 2007, p. 229.

${ }^{49}$ En la Historia de Ley $N^{\circ} 20.417$, no se observa una mayor atención ni discusión respecto de la calidad de interesado que se le daba al denunciante. No obstante, se lee frecuentemente de la discusión parlamentaria que la denuncia tenía por finalidad permitir la participación ciudadana en las materias sancionatorias ambientales. V. BiblioteCA Del Congreso Nacional, Historia de la Ley $N^{\circ} 20.147$ de 2010, documento digital, BCN, Santiago, 2010, disponible en línea: https://www.bcn.cl/historiadelaley/ nc/historia-de-la-ley/4798/.

${ }^{50}$ A partir de la sentencia de la Corte Suprema, 3 de agosto de 2017, Rol № 38340-2016, se puede decir que la denuncia no solo es un mecanismo para internalizar socialmente la fiscalización sino además es la forma en que un organismo sectorial que, en el ámbito de sus competencias y potestades, detecta un incumplimiento de carácter ambiental debe actuar en sus relaciones con la SMA.
} 
que subyacen en el artículo 21 LOSMA se vinculan a la participación y colaboración de los ciudadanos en la fiscalización y control de la actividad administrativa en materia ambiental. En este sentido, el denunciante no debe alegar ni probar en el proceso que la resolución de la SMA le genera un perjuicio para entender que se encuentra legitimado. Tal como se ha dicho, el denunciante podría simplemente invocar el interés público en el cumplimiento de la legalidad y ese interés es suficiente para entender que está legitimado. ${ }^{51}$

Teniendo claro lo anterior, la pregunta que debe formularse es la siguiente: ¿Puede ser discutida la legitimación del denunciante en sede jurisdiccional? La propuesta de este trabajo es que si los denunciantes esconden intereses espurios (como por ejemplo el interés de que no exista competencia $)^{52}$ bajo el manto de legitimidad que le brinda el interés público, podría ser derrotada la norma. En efecto, cuando en un denunciante concurre un interés espurio se produce una "experiencias recalcitrantes", en la medida que la justificación subyacente del artículo 21 LOSMA, que es incentivar la participación ciudadana en la protección del medio ambiente, no resulta aplicable a esos casos. Si la justificación de la norma es posibilitar el ejercicio de la participación ciudadana otorgando una retribución al que formula una denuncia que permite iniciar un procedimiento sancionador; esta justificación no resulta aplicable cuando el denunciante, en realidad, busca beneficios o utilidades individuales no conciliables con el interés público, y que invocando el interés individual no lograría satisfacer. En estos casos los TTAA podrían revisar si efectivamente el denunciante puede considerarse interesado y, en consecuencia, descartar su legitimación activa

\footnotetext{
${ }^{51}$ Por otra parte, existen terceros que desean intervenir directamente ante el TTAA invocando un interés público, para lo cual la LTTAA establece el mecanismo del amicus curiae (artículo 19 LTTAA). En este caso los terceros puedan participar del contencioso administrativo ambiental, no en calidad de parte, sino dando una opinión técnica con sus comentarios, observaciones y sugerencias respecto de la materia objeto del proceso.

${ }^{52}$ Cabe señalar que el artículo 3 de la Ley No 20.169 de 2007, indica que "En general, es acto de competencia desleal toda conducta contraria a la buena fe o a las buenas costumbres que, por medios ilegítimos, persiga desviar clientela de un agente del mercado". Agregando en su artículo 4: "En particular, y sin que la enumeración sea taxativa, se considerarán actos de competencia desleal los siguientes: letra g) El ejercicio manifiestamente abusivo de acciones judiciales con la finalidad de entorpecer la operación de un agente del mercado". Es evidente que el ejercicio de acciones judiciales que tienen una legitimación popular constituye una herramienta para instrumentalizar actos contrarios a la competencia, especialmente en proyectos de cierta envergadura. Esta sería una forma ex post de reprimir el ejercicio de acciones judiciales cuyo propósito no es velar por el medio ambiente sino ejecutar actos de competencia desleal. La propuesta de este trabajo, sin embargo, es impedir, vía legitimación, que el proceso jurisdiccional se convierta en una forma de competencia desleal.
} 
por no estar afectado por la resolución que dicta la SMA.

La anterior afirmación implica justificar dos cuestiones. La primera se relaciona con la conceptualización del "interés espurio", y; la segunda, con la alegación y prueba de este interés en el contexto del contencioso administrativo ambiental. Sobre lo primero no existe en Chile ni en el Derecho Comparado estudios específicos que se detengan a analizar con precisión qué debe entenderse por "interés espurio". No obstante, para efectos de este trabajo, entenderemos por tal al interés no legítimo. Como indica Gómez DíAz "la exigencia de legitimidad del interés supone, en primer lugar, la negación de eficacia legitimadora a las situaciones de base que sean contrarias al ordenamiento jurídico, o incompatibles u opuestas a los valores y directivas constitucionales; nadie debe poder recurrir una actuación administrativa, en suma, para defender el mantenimiento de una situación ilegítima". ${ }^{53}$ De esta forma, es posible reconocer dos hipótesis en que nos encontraríamos con un interés espurio: primero, cuando la posición jurídica que defiende el denunciante es contraria al ordenamiento jurídico, esto es, se encuentra en oposición a la ley o el reglamento. En segundo lugar, cuando la posición del denunciante es incompatible con los valores o bienes que constitucionalmente se estiman relevantes. Este es caso de quien, por medio de la denuncia y posterior ejercicio de una acción judicial, pretende entorpecer y/o eliminar la competencia, desprestigiar a un regulado o simplemente estorbar el ejercicio de un proyecto o actividad. El interés de que no exista competencia en una determinada actividad económica no puede ser considerado un interés legítimo. Nuestro ordenamiento jurídico, por un lado, sustenta su ideario económico en la libre iniciativa privada en una estructura de competencia de mercado, valores que están constitucionalmente previstos (artículos $19 \mathrm{~N}^{\circ} \mathrm{s} 24$ y $21 \mathrm{CPR}$ ), y por el otro, protege legalmente las dinámicas de los mercados libres y competitivos (DL 211 de 1973, y sus posteriores modificaciones, y Ley 20.169, que regula la Competencia Desleal).

Si bien esta fórmula parece muy laxa e indeterminada, habría que aplicarla solo en los casos en que la contradicción aparece grave, explícita y relevante. ${ }^{54}$ Estas posiciones no son amparadas por el derecho, y por tal

\footnotetext{
${ }^{53}$ GómEZ, cit. (n. 38), p. 254.

${ }^{54}$ GómEz, cit. (n. 38), p. 254. Es preciso indicar que la noción de interés legítimo, atendida su amplitud, carece de contornos precisos, y la doctrina suele identificarlo como aquella ventaja o beneficio que es digna de protección o tutela. V. GonZÁlez, cit. (n. 31), pp. 41 y siguientes. Por esta razón definir un interés no legítimo suele presentar idénticas dificultades que escapan del objetivo de este trabajo.
} 
razón, debiesen carecer de toda posibilidad de tutela judicial efectiva. Ambas situaciones, en la medida que no se condicen con las razones subyacentes del artículo 21 LOSMA, permitirían al Tribunal Ambiental considerar el interés del impugnante al momento de resolver la reclamación.

Por otro lado, también es relevante señalar que la develación de estos intereses espurios deberá ser objeto de alegación y prueba, generalmente del reclamado pero también del que comparezca como tercero. A falta de esa alegación y prueba, rige la regla con todos sus efectos, esto es, que el denunciante tiene legitimación para promover el ejercicio del aparato jurisdiccional. Evidentemente se trata de una prueba que no se logrará de forma directa, debiendo recurrirse a los indicios o presunciones.

\section{CONCLUSIONES}

De acuerdo al artículo 21 LOSMA, el denunciante adquiere, por el solo ministerio de la ley, la calidad de interesado cuando producto de su denuncia la SMA inicia un procedimiento sancionador. El legislador, en este sentido, considera interesado al denunciante sin requerirle una justificación y prueba de ser titular de derechos e intereses legítimos que pueden resultar afectados. Con todo, habrá ocasiones en que el denunciante tenga la calidad de interesado, dado que su posición jurídica se encuentra en conexión con la decisión sancionatoria. En otras ocasiones, en cambio, el denunciante no tendrá vinculación alguna con el objeto del procedimiento administrativo. En rigor el denunciante es una fuente de información para determinar la infracción a la normativa ambiental, pues ha tomado conocimiento de ella y ha dado la notitia criminis a la Administración para el ejercicio del ius puniendi.

En este sentido es posible entender el artículo 21 LOSMA en un doble sentido: primero creer que esta norma es una especificación del artículo 21 LBPA, es decir, exige que el denunciante sea titular de derechos e intereses legítimos, individuales o colectivos, pero éstos se subentienden o presumen. El segundo sentido es seguir el tenor literal de la disposición que es categórico en afirmar que el denunciante adquiere la calidad de interesado, sea que detente o no posiciones jurídicas subjetivas. En este último es perfectamente posible afirmar que el denunciante puede actuar en el puro interés del cumplimiento de la legalidad ambiental. Aquí las consecuencias en relación a la posibilidad sancionatoria son evidentes. El denunciante puede recurrir a los TTAA cuando estime que la resolución dictada por la SMA no satisfaga adecuadamente el interés público. 
Ahora bien, el problema de reconocer esta clase de legitimación es que bajo el pretendido cumplimiento de la legalidad pueden esconderse intereses de todo orden, mucho de los cuales no pueden considerarse legítimos. Por eso parece razonable autorizar al intérprete para derrotar la regla del artículo 21 LOSMA cuando existe una "experiencia recalcitrante", esto es, cuando las razones subyacentes en la formulación de la regla no se encuentran presentes en su aplicación. Este problema de adecuación entre formulación normativa y justificación subyacente se produce cuando la primera es supraincluyente, esto es, la prescripción incorpora ciertos supuestos en los que no sería aplicable la justificación.

En este sentido, el artículo 21 LOSMA es una norma cuya finalidad es impulsar la participación ciudadana en la fiscalización ambiental a través de un incentivo y retribución hacia el denunciante. Si se considera que una denuncia sobre el incumplimiento de un instrumento de gestión ambiental es socialmente beneficiosa y que tiende a la protección del medio ambiente, transformar al denunciante en un interesado es un incentivo adecuado para estimular la participación de la ciudadanía en la fiscalización ambiental. Cuando estas razones subyacentes no se encuentran presentes, y es posible entender que el denunciante enarbola intereses que no se consideran legítimos, los TTAA pueden revisar y controlar la legitimación. De esta forma la norma en cuestión es derrotada en su aplicación con miras a evitar que se avalen situaciones jurídicas que no están presentes en las razones subyacentes.

\section{BIBLIOGRAFÍA CITADA}

\section{A) Doctrina}

BAYON, Juan Carlos, "Derrotabilidad, indeterminación del derecho y positivismo jurídico", Isonomía, 2000, $\mathrm{N}^{\circ} 13$, pp. 87-117.

BERMÚDEZ, Jorge, "Administración y Jurisdicción Ambiental: la institucionalidad ambiental frente al nuevo contencioso administrativo", en: FerradA, Juan C. (Coord.), La nulidad de los actos administrativos en el derecho chileno. IX Jornadas de Derecho Administrativo, Thomson Reuters, Legalpublishing, Santiago, 2013, pp. 485-511.

Bermúdez, Jorge, Fundamentos de Derecho Ambiental, Ediciones Universitarias de Valparaíso, Valparaíso, 2014, $2^{\text {a }}$ Edición.

Biblioteca del Congreso Nacional, Historia de la Ley No 20.147 de 2010, 
documento digital, BCN, Santiago, 2010, disponible en línea: https://www.bcn.cl/ historiadelaley/nc/historia-de-la-ley/4798/.

Bordali, Andrés; Hunter, Iván, Contencioso Administrativo Ambiental, Librotecnia, Santiago, 2017.

Bordalí, Andrés, "La Administración Pública ante los Tribunales de Justicia Chilenos", Revista Chilena de Derecho, 2006, Vol. 33, № 1, pp. 17-36.

Bordalí, Andrés, "Principios de una nueva justicia administrativa en Chile", en: Bordalí, A.; Ferrada, J. C. (Coords.), Estudios de Justicia Administrativa, LexisNexis, Santiago, 2008, pp. 341-381.

Calvo, María, Sanciones ambientales, Marcial Pons, Madrid, 1999.

CARLONI, Enrico, Le verità amministrative. L'attività conoscitiva pubblica tra procedimento e proceso, Giuffrè Editore, Milán, 2011.

Cово, Tomás, El procedimiento administrativo sancionador, Editorial Bosch, Barcelona, 2008.

Cordero, Eduardo, "La legitimación activa en el proceso contenciosoadministrativo", en: Ferrada, J. C. (Coord.), La Justicia Administrativa, Lexis Nexis, Santiago, 2005, pp. 383-416.

Cordón, Faustino, El Proceso Contencioso Administrativo, Conforme a la Ley 29/1998 de 13 de julio, reguladora de la Jurisdicción ContenciosoAdministrativa, Aranzadi, Madrid, 2001, Segunda edición.

DomÉnECH, Gabriel, "Roma delatoribus praemiat. La denuncia en el Derecho Público", en: Díez, Juan José (Ed.), Función Inspectora. Actas del VIII Congreso de la Asociación Española de Profesores de Derecho Administrativo, Instituto Nacional de Administración Pública, Madrid, 2013, pp. 171-187.

Domínguez, Antonio, Constitución y Derecho Sancionador Administrativo, Marcial Pons, Madrid, 1997.

Ferrada, Juan Carlos, "La legitimación activa en los procesos administrativos anulatorios en el derecho chileno", en: Ferrada, J. C. (Coord.), La nulidad de los actos administrativos en el derecho chileno, Thomson Reuters, Legalpublishing, Santiago, 2013, pp. 157-187.

Gallardo, María Jesús, Los procedimientos administrativos en la Ley 39/2015: análisis y valoración de la reforma, Editorial Tecnos, Madrid, 2016.

Gómez, Ana, La legitimación en el proceso contencioso-administrativo, Iustel, Madrid, 2014.

Gómez, Manuel; Sanz, Iñigo, Derecho Administrativo Sancionador Parte General. Teoría General y Práctica del Derecho Penal Administrativo, Aranzadi, Madrid, 2013, $3^{\text {a }}$ edición.

GonZÁlez, Isabel, La protección de los intereses legítimos en el proceso administrativo, Tirant lo Blanch, Valencia, 1997.

GonzÁlez, Jesús, Manual de Procedimiento Administrativo, Civitas, Madrid, 2002, $2^{\text {a }}$ Edición. 
GuAstini, Riccardo, Estudios sobre la interpretación jurídica (Trad. Miguel Carbonell y María Gascón), Universidad Nacional Autónoma de México, Ciudad de México, 1999, $1^{\text {a }}$ Edición.

Huergo, Alejandro, Las sanciones administrativas, Iustel, Madrid, 2007.

JARA, Jaime, La nulidad de Derecho Público ante la doctrina y la jurisprudencia, Editorial Libromar, Santiago, 2004.

LozAno, Blanca, "El principio de oficialidad de la acción sancionadora administrativa y las condiciones necesarias para garantizar su efectividad", Revista de Administración Pública, 2003, N 161, pp. 83-121.

Martínez, Nora, "Problemas jurídico-prácticos de la figura del denunciante en el procedimiento administrativo sancionador", Revista Xuridica Galega, 2001, $\mathrm{N}^{\circ} 33$, pp. 60-89.

Moreso, Juan; Vilajosana, Josep, Introducción al Derecho, Marcial Pons, Madrid, 2004.

Navarro, Manuel, Partes, legitimación y litisconsorcio en el proceso civil (Estudio jurisprudencial práctico), Colex, Madrid, 1998.

Nieto, Alejandro, Derecho Administrativo Sancionador, Tecnos, Madrid, 1993.

Orena, Aitor, Discrecionalidad, Arbitrariedad e Inicio de Actuaciones Inspectoras, Aranzadi, Navarra, 2006.

Parejo, Luciano, Derecho Administrativo, Ariel, Barcelona, 2003.

Parejo, Luciano, Lecciones de Derecho Administrativo, Tirant lo Blanch, Madrid, 2012.

PÉrez, Lorenzo, La defensa de los intereses ambientales (Estudio especifico de la legitimación 'difusa' en el proceso contencioso administrativo), Editorial Lex Nova, Valladolid, 2002.

Prieto, Hugo, "La acción popular en el proceso administrativo" en: CASSAGNe, J. C. (Director), Derecho Procesal Administrativo 1, Editorial Hammurabi, Buenos Aires, 2004.

RóDENAS, Ángeles, "En la penumbra: indeterminación, derrotabilidad y aplicación judicial de normas", Doxa: Cuadernos de Filosofía del Derecho, 2001, $\mathrm{N}^{\circ} 24$, pp. 63-83.

Romero, Alejandro, "Comentario a la sentencia de la Corte Suprema y de la Corte de Apelaciones de Santiago y de Puerto Montt. Nota sobre la legitimación en la jurisprudencia", Revista Chilena de Derecho, 1998, Vol. 25, pp. 691-693.

Ruiz, Francisco, El proceso contencioso-administrativo, Thomson Aranzadi, Pamplona, 2016.

Santamaría, Juan, Principios de Derecho Administrativo General, Iustel, Madrid, 2009, $2^{\text {a }}$ Edición, Tomo II.

SCHAUER, Frederick, Las reglas en juego. Un examen filosófico de la toma de decisiones basadas en reglas en el derecho y en la vida cotidiana, Marcial Pons, 
Madrid, 2004.

Tolosa, César, "Proceso contencioso y medio ambiente: cuestiones procesales", Revista Jurídica de Castilla y León, 2010, № 21, pp. 13-49.

B) Normas citadas

Constitución Política de la República

Ley $\mathrm{N}^{\circ} 19.300,1994$.

Ley $\mathrm{N}^{\circ} 19.880,2003$.

Ley $\mathrm{N}^{\circ} 20.470,2010$.

Ley $\mathrm{N}^{\circ} 20.600,2012$.

Historia de la ley 20.417

Ley $\mathrm{N}^{\circ} 20.169,2007$.

Decreto Ley $\mathrm{N}^{\circ} 211,1973$.

\section{C) Jurisprudencia citada}

Corte Suprema, 3 de agosto de 2017, Rol N 38340-2016.

Corte Suprema, 30 de septiembre de 2015, Rol No 1119-2015.

Segundo Tribunal Ambiental, 3 de marzo de 2014, Rol N R-6-2013.

Segundo Tribunal Ambiental, 19 de junio de 2014, Rol N R-20-2014.

Segundo Tribunal Ambiental, 16 de diciembre de 2014, Rol N R-22-2014.

Segundo Tribunal Ambiental, 22 de julio de 2016, Rol N R-68-2015.

Segundo Tribunal Ambiental, 24 de febrero de 2017, Rol No R-104-2016.

Segundo Tribunal Ambiental, 31 de agosto de 2017, Rol N R-118-2016.

Tercer Tribunal Ambiental, 29 de septiembre de 2016, Rol N R-25-2016. 